\title{
Organic Food Appeals to Intuition and Triggers Stereotypes
}

\author{
Marjaana Lindeman ${ }^{1} \&$ Joonas Anttila $^{1}$ \\ ${ }^{1}$ Department of Psychology and Logopedics, University of Helsinki, Finland \\ Correspondence: Marjaana Lindeman, Department of Psychology and Logopedics, 00014 University of Helsinki, \\ Finland.
}

Received: August 6, 2018

Accepted: August 20, 2018

Online Published: August 24, 2018

doi:10.5539/ijps.v10n3p66

URL: https://doi.org/10.5539/ijps.v10n3p66

\begin{abstract}
Evidence suggests that the benefits of organic food are overstated. In study 1, factors predicting positive attitudes toward organic food (OF), food processing and additives were investigated. Intuitive thinking style was the strongest predictor, followed by categorical thinking, belief in simplicity of knowledge and susceptibility to health myths. In Study 2, the effect of OF consumer status on perceived warmth and competence was examined. OF-positive participants rated the OF consumer similarly as the conventional consumer. However, OF-negative participants regarded the OF consumer as warmer but less competent than the conventional consumer. In Study 3, perceptions of a couple were examined similarly. OF consumer couple's relationship was more idealized by the OF-positive participants whereas other participants regarded the OF consumer couple's relationship as less satisfactory. In addition, intuitive thinking style increased positive judgments about the stimulus persons in Studies 2 and 3. Eating organic food may thus evoke positive and negative stereotypes, and intuitive thinkers may be especially receptive to OF marketing and influenced by a preference for natural.
\end{abstract}

Keywords: organic food, attitudes, stereotypes, thinking styles

\section{Introduction}

One of the biggest food trends right now is organic food. In the United States, for example, the sales multiplied from 13.3 million dollars in 2005 to nearly 40 million dollars in 2015 (Statista, n.d.). Europe follows the same trend. The consumption of organic food increased in the EU market by $110 \%$ between 2005 and 2014 whereas household consumption of food in general remained almost constant (IFOAM EU Group, 2016). Consumers prefer organic products because they are considered healthier, safer, environmentally more friendly, better for animal welfare, and superior in taste compared with conventional products (reviews: Hughner, McDonagh, Prothero, Shultz, \& Stanton, 2007; Prada, Rodrigues, \& Garrido, 2016). Products labelled as organic are rated as having a better taste than their conventional counterparts even when the products are identical (Sörqvist et al., 2015; Wiedmann, Hennigs, Henrik Behrens, \& Klarmann, 2014).

While the benefits may exist in some specific cases, scientific evidence does not warrant these overarching positive attitudes. Reviews and meta-analyses show that the nutrient quality of organically and conventionally produced food do not differ (Dangour et al., 2009; Dangour et al., 2010; Rosen, 2010; Smith-Spangler et al., 2012; Williams, 2002), and that the findings about organic food safety and less adverse environmental impact are inconclusive and variable (Magkos, Arvaniti, \& Zampelas, 2006; Seufert, Ramankutty, \& Foley, 2012; van Huylenbroek et al., 2009). However, the marketing of organic food has been so one-sidedly positive that it has been regarded as based on misleading perceptions of non-organic food by the Academics Review association (n.d.).

One of the most common attributes that consumers and marketers associate with organic food is naturalness (Hsu, Chang, \& Lin, 2016; Lockie, Lyons, Lawrence, \& Grice, 2004). Naturalness per se, however, is not a self-evident justification for positive attitudes. Many natural substances, including such everyday foods as apples and potatoes, contain noxious compounds; and ingestion of plants may cause allergies, intoxication, and even death. In turn, advances in chemically processed medicines and food additives have improved health-care, increased food safety, and led globally to a longer and healthier life span.

The above issues call for further research on attitudes toward organic foods. Although previous studies have extensively examined consumers' beliefs about organic food, psychological factors influencing OF attitudes are not known. We therefore designed three studies to address these issues. 


\subsection{Study 1}

Our first research question is how two common thinking styles, intuitive and analytical styles, predict attitudes toward organic foods. People with a strong intuitive style use mental shortcuts in decision making and like to rely on their feelings as a guide for actions. They also think in terms of broad polarized categories, and prefer thoughts that come to mind quickly without much reflection (Hodgkinson, Langan-Fox, \& Sadler-Smith, 2008; Norris \& Epstein, 2011). Those with a strong analytical style engage in and enjoy effortful cognitive activity, seek various points of view before drawing conclusions, and calibrate the strength of their opinions to the degree of evidence available (Epstein, Pacini, Denes Raj, \& Heier, 1996; Stanovich, 2012). Thinking styles are thus trait-like concepts, reflecting the habitual use of intuitive or analytical thinking, respectively.

To our knowledge, only one study has directly examined the role of thinking styles in OF attitudes. In line with these findings Saher, Lindeman, and Koivisto-Hursti (2006), we expect that positive OF attitudes increase when intuitive thinking style increases. This association is plausible. Although most people think positively about what is natural (Li \& Chapman, 2012; Rozin et al., 2004), it is especially intuitive thinkers whose beliefs rely heavily on what feels good (Epstein et al., 1996; Slovic, Finucane, Peters, \& MacGregor, 2004). Similarly, although attitudes are generally enhanced by mere exposure (Zajonc, 1968), it is consumers who trust their feelings who are particularly susceptible to believing in a product claim simply because the claim is repeated (Sundar, Kardes, \& Wright, 2015). Finally, one main explanation that people offer for their preference for what is natural is that it "simply feels right" (Rozin, 2005), also indicating the role of intuition in the assessment of organic and other natural products.

Although Saher et al. (2006) found no relationship between analytical thinking style and OF attitudes, we expect that compared with non-analytical people, analytical thinkers are more critical of organic foods. First, Saher et al. (2006) assessed analytical and intuitive thinking styles with only two scales, Faith in Intuition and Need for Cognition, so more diverse methods are necessary to confirm the findings. Second, the study was conducted more than a decade ago, and exposure to OF information over the years may have changed the situation. Finally, consumers who rely on analytical thinking are more likely to inspect product claims more than are people with a low need for cognition (Haugtvedt, Petty, \& Cacioppo, 1992).

In the present study, the following hypotheses are set. We expect positive OF attitudes to increase with intuitive thinking style (Hypothesis 1) and to decrease with analytical thinking style, operationalized here as the need for cognition (Hypothesis 2). We also hypothesize (3) that those who succeed in the Cognitive Reflection Test are more critical of organic food than others because correct responses in the test require analytical thinking (Frederick, 2005). Given the one-sidedness of organic food marketing, and because intuitive thinkers tend to perceive reality in terms of polarized categories, we expect that positive OF attitudes are related to categorical thinking about food and eating (Hypothesis 4) and to thinking that knowledge is something that is simple rather than complex (Hypothesis 5). Finally, because the idea that organic foods are self-evidently better than other products can be considered a myth, that is, a collectively common but unproven (or even false) belief, we examine whether positive attitudes toward organic foods increase with susceptibility to health and food related myths in general.

To complement the examination of attitudes toward organic food, we will also examine attitudes toward avoiding processed food and food additives. Consumers typically characterize organic food as something that does not include additives and that has not undergone any "processes", that is, human-induced transformations (e.g., Rozin, 2005; Rozin, Fischler, \& Shields-Argelès, 2012). Overall, high level of food processing has been shown to be incongruent with the idea of organic food (Arvola et al., 2008; Prada, Garrido, \& Rodrigues, 2017). Most of the results should therefore be similar for attitudes toward favoring organic food, and for avoiding food additives and processed food.

\subsection{Pilot Study}

To ascertain that also individuals in Finland understand processed food as something that is not natural or organic, twenty-seven students of psychology (mean age $=24.15,70.4 \%$ women) were asked how they understand "the vague expression of processed food." Of the 32 explanations given, 19 focused on various food additives or gene manipulation, five included the idea that the food is commercially prepared, and only eight focused on preparing food at home or digesting food. These findings give further support to the idea that food processing often evokes an association with unnatural food. 


\subsection{Method}

\subsubsection{Participants and Procedure}

Four hundred and fifty-two Finnish individuals took part in the online study. Their mean age was 31 years $(S D=$ 11.26 , range $16-55$ ), and $28.3 \%$ were working, $58.9 \%$ were students, and $12.4 \%$ were otherwise occupied. (The figures do not sum up to $100 \%$ because of missing data.) Of the participants, $76.3 \%$ were women and $19.3 \%$ were men. Some (1.7\%) did not want to state their sex or rated their sex as other than male or female (1.5\%). Because these groups were small, they were excluded from analyses that included sex comparisons.

The participants were recruited for the online study via several open internet discussion forums and student mailing lists. They were told that the study concerned food, values and thinking, and confidentiality and voluntary participation were emphasized. As compensation, all participants were offered feedback about their responses on some of the scales included in the survey.

Because the response rate of online surveys is hard to predict and the ideal sample size for this kind of study may be quite larger than minimum recommendations, we made the online study available for seven weeks (including the festive season). According to Tabachnick and Fidell's (2013) rule of thumb, $\mathrm{N}>104+\mathrm{m}$ (where $\mathrm{m}$ stands for the number of predictors) is recommended for testing individual predictors at $\alpha=.05$ to attain $80 \%$ power in a regression analysis, for example. However, an even bigger sample is necessary to allow for skewness of the dependent variable or substantial measurement error, and to detect even weak relationships between variables (which are potentially interesting when examining a phenomenon not well understood).

\subsubsection{Material}

Attitudes toward organic food were assessed by a semantic differential including four 5-point items from (Sparks $\&$ Shepherd, 1992). The participants were asked to rate their attitudes toward consuming organic products with the following polar adjectives: foolish (1) - wise (5), bad (1) - good (5), harmful (1) - beneficial (5), and unpleasant (1) - pleasant (5). The scores were averaged to form a composite score. Here, as with all the other composite variables, the composite variable was not calculated if the participant had $25 \%$ or more missing items on the scale. The reliability estimate (Cronbach's $\alpha$ ) of the four items in the scale was .88 .

Attitudes toward avoiding food additives $(\alpha=.93)$ and toward avoiding food processing $(\alpha=.89)$ were otherwise measured similarly as OF attitudes but the participants were asked to rate their attitudes toward avoiding "E codes" (i.e., codes for additives that are permitted to be used in food within the European Union) and avoiding processed food.

Intuitive thinking style was assessed with the 10 -item Faith in Intuition subscale $(\alpha=.80)$ from the Rational/Experiential Multimodal Inventory (REIm, Norris \& Epstein, 2011). The items were rated on a four-point scale ( 1 = strongly disagree, $4=$ strongly agree $)$. An example item is: "I like to rely on my intuitive impressions." Analytical thinking style was assessed with the 12-item Need for Cognition, a.k.a., Rationality subscale $(\alpha=.83)$ from the REIm. An example item is: "I enjoy intellectual challenges."

We also included a performance measure of analytical thinking, the Cognitive Reflection Test $(\alpha=.70$, Frederick, 2005). It consists of three questions that cue intuitive but incorrect responses that must be resisted to calculate the correct answers (e.g., "A bat and a ball cost $€ 1.10$ in total. The bat costs $€ 1$ more than the ball. How much does the ball cost?"). The composite score was operationalized as the number of correct responses in the test.

Categorical thinking $(\alpha=.67)$ in the context of eating was measured with six 5-point items $(1=$ strongly disagree, 5 = strongly agree). One of the items ("I think of food as either good or bad") was from the Dichotomous Thinking in Eating Disorders Scale (Byrne, Allen, Dove, Watt, \& Nathan, 2008). Two items were from Rothgerber's (2015) study (e.g., "There is never a good enough reason to violate my diet"). The final three items were obtained from (Rozin, Ashmore, \& Markwith, 1996) study (e.g., "If something can cause harm to the body in large amounts, then it is always better not to eat it even in small amounts").

The questionnaire of simplicity of knowledge $(\alpha=.82)$ included seven items on beliefs about the structure of knowledge (simple vs. complex), modified after the items in the Epistemic Beliefs Inventory (Schraw, Bendixen, $\&$ Dunkle, 2002) and the Epistemological Questionnaire (Schommer, 1990). An example items is "Things are simpler than most professionals would have you believe".

Susceptibility to health myths was assessed with 12 items $(\alpha=.68 ; 1=$ strongly disagree, $5=$ strongly agree). Five items were derived from the Belief in Science-Related Myths scale (Swami, Stieger, Pietschnig, Nader, \& Voracek, 2012). Examples include "We only use 10\% of our brains" and "Chewing-gum takes seven years to pass through the human digestive system." Other items were derived from websites that dealt with health myths 
(e.g., "You should drink eight glasses of water per day". Four (correct) filler items were also included in the scale (e.g., "Red-green color blindness is more prevalent among males than females"). The response time to complete the entire 12-item scale was limited to two minutes, so that the participants would not have time to check the correct response from the internet, for example.

\subsection{Results}

Positive skewness was found for OF attitudes (skewness $=-0.84$, Kolmogorov- Smirnov $Z=0.15, p<.001$ ) and for attitudes toward processed food (skewness $=-0.67$, Kolmogorov- Smirnov $Z=0.12, p<.001$ ). We therefore calculated Spearman's rho $\left(r_{s}\right)$ for the variables (Table 1).

Table 1. Spearman Correlations Between the Cognitive Variables and Positive Attitudes Towards Consuming Organic Food and Avoiding Food Additives and Processed Food

\begin{tabular}{lllllllll}
\hline & 1 & 2 & 3 & 4 & 5 & 6 & 7 & 8 \\
\cline { 2 - 8 } 1. Organic food & & & & & & & & \\
2. Food additives & $.57^{* * *}$ & & & & & & & \\
3. Processed food & $.52^{* * *}$ & $.61^{* * *}$ & & & & & & \\
4. Intuitive style & $.41^{* * *}$ & $.34^{* * *}$ & $.29^{* * *}$ & & & & & \\
5. NfC & $-.13^{* *}$ & $-.18^{* * *}$ & $-.11^{*}$ & $-.35^{* * *}$ & & & & \\
6. CRT & $-.21^{* * *}$ & $-.20^{* * *}$ & $-.15^{* *}$ & $-.23^{* * *}$ & $.33^{* * *}$ & & & \\
7. Categorical & $.25^{* * *}$ & $.26^{* * *}$ & $.18^{* * *}$ & $.19^{* * *}$ & $-.16^{* *}$ & $-.23^{* * *}$ & & \\
8. Simplicity & $.28^{* * *}$ & $.36^{* * *}$ & $.24^{* * *}$ & $.38^{* * *}$ & $-.35^{* * *}$ & $-.17^{* * *}$ & $.29^{* * *}$ & \\
9. Health myths & $.31^{* * *}$ & $.36^{* * *}$ & $.25^{* * *}$ & $.40^{* * *}$ & $-.25^{* * *}$ & $-.17^{* * *}$ & $.18^{* * *}$ & $.32^{* * *}$ \\
\hline
\end{tabular}

$\overline{\text { Note. } \mathrm{NfC}=\text { Need for Cognition, } \mathrm{CRT}=\text { Correct responses in the Cognitive Reflection Test, Categorical }}=$ Categorical thinking style, Simplicity $=$ Beliefs that knowledge is simple

$*<.05 .{ }^{* *} \mathrm{p}<.01 .{ }^{* * *} \mathrm{p}<.001$.

To examine the unique contributions of the cognitive variables to the prediction of the attitude variables, sequential multiple regressions were conducted (Table 2). The control variable of gender was entered in Step 1 because women's attitudes differed from men's attitudes: Women rated OF foods more positively $(M=4.32)$ than men $\operatorname{did}(M=3.87), F(2,409)=12.79, p<.001, \eta_{p}{ }^{2}=.059$. They also rated avoidance of food additives more positively $(M=3.28)$ than men $\operatorname{did}(M=3.01), F(2,402)=3.14, p=.044, \eta_{p}{ }^{2}=.015$, and avoidance of processed food more positively $(M=4.01)$ than men $\operatorname{did}(M=3.58), F(2,400)=7.84, p<.001, \eta_{p}{ }^{2}=.039$. Age was not associated with the three attitudes $\left(p^{\prime} \mathrm{s}>.17\right)$.

Examination of residuals scatterplots showed that assumptions of normality and linearity between predicted DV scores and errors of prediction were met. However, some heteroscedasticity was found. This does not invalidate the results but may weaken the analysis so that the full extent of the relationships among the dependent and independent variables is not mapped (Tabachnick \& Fidell, 2013).

The regression analysis showed that intuitive thinking style, categorical thinking about food, believing that knowledge consists of simple facts, and susceptibility to health myths were significant predictors of positive OF attitudes. The same variables predicted positive attitudes toward avoidance of food additives and processed food. Apart from the marginally significant influence of need for cognition on avoiding processed food, need for cognition or correct responses on the Cognitive Reflection Test did not predict any of these three attitudes. 
Table 2. Regression Analyses Predicting Positive Attitudes Towards Consuming Organic Food and Avoiding Food Additives and Processed Food

\begin{tabular}{|c|c|c|c|c|c|c|c|c|c|c|c|c|}
\hline & \multicolumn{4}{|c|}{ Organic food } & \multicolumn{4}{|c|}{ Food additives } & \multicolumn{4}{|c|}{ Processed food } \\
\hline & $\Delta R^{2}$ & $\beta$ & $\mathrm{t}$ & $\mathrm{p}$ & $\Delta R^{2}$ & $\beta$ & $\mathrm{t}$ & $\mathrm{p}$ & $\Delta \mathrm{R}^{2}$ & $\beta$ & $\mathrm{t}$ & $\mathrm{p}$ \\
\hline Step1 & .03 & & & & .01 & & & & .02 & & & \\
\hline Gender & & .18 & 2.73 & $<.001$ & & .07 & 1.26 & .21 & & .14 & 2.59 & .01 \\
\hline Step 2 & .24 & & & & .24 & & & & .14 & & & \\
\hline $\begin{array}{l}\text { Intuitive } \\
\text { style }\end{array}$ & & .26 & 4.54 & $<.001$ & & .19 & 3.29 & $<.001$ & & .19 & 3.06 & .01 \\
\hline $\mathrm{NfC}$ & & .06 & 1.19 & .24 & & .04 & 0.69 & .49 & & .10 & 1.74 & .08 \\
\hline CRT & & -.06 & -1.20 & .23 & & -.06 & -1.10 & .28 & & -.05 & -0.83 & .41 \\
\hline Categorical & & .14 & 2.76 & .01 & & .18 & 3.60 & $<.001$ & & .10 & 1.92 & .06 \\
\hline Simplicity & & .11 & 2.00 & .05 & & .12 & 2.13 & .03 & & .11 & 1.89 & .06 \\
\hline $\begin{array}{l}\text { Health } \\
\text { myths }\end{array}$ & & .14 & 2.56 & .01 & & .23 & 4.40 & $<.001$ & & .12 & 2.09 & .04 \\
\hline
\end{tabular}

Note. $\mathrm{NfC}=$ Need for Cognition, $\mathrm{CRT}=$ Correct responses in the Cognitive Reflection Test, Categorical $=$ Categorical thinking style, Simplicity $=$ Beliefs that knowledge is simple

\subsection{Discussion}

The results were fully in line with Saher et al.'s (2006) study in that intuitive thinking style, as measured by the Faith in intuition scale, increased together with positive OF attitudes, whereas the role of analytical thinking style, as measured by need for cognition, was weakly related to OF attitudes. The present results also extend the previous findings by showing that these relationships were not limited to thinking styles assessed by REIm but were detected by several other measures of intuitive and analytical style as well. The same variables predicted attitudes toward organic food, toward avoiding food additives, and toward processed food, indicating their close relationship.

Reliance on intuition may also affect the way organic food users are seen because intuitive thinking can predispose people to stereotypes (Epstein et al., 1996; Kahneman \& Frederick, 2002). However, a positive attitude toward organic food is not (only) an intrapersonal characteristic but like other attitudes, it is essentially a social phenomenon. It is acquired in social interaction in a specific culture, it is socially shared, and it can thus influence social perception. The purpose of Study 2 was therefore to examine how attitudes toward organic food influence perception of individuals who use organic food.

\section{Study 2}

Food is a powerful source for stereotypes. Several studies have shown how easily people attribute different kinds of personality traits, like masculinity or high morality, to strangers based only on the type or amount of food they eat (reviews: Vartanian, 2015; Vartanian, Herman, \& Polivy, 2007). Even eating organic food affects the way a person is perceived by others. Compared with people who eat a conventional meal, people who choose an organic meal are evaluated more leniently if they skip their exercise (Prada et al., 2016). From studies based on person perception we also know that similarity to a person with respect to attitudes is largely associated with increased attraction (a review: Montoya \& Horton, 2013). This also applies to food: people who identify themselves as environmentally friendly consumers, feel attached to consumers who buy organic food products (Bartels \& Hoogendam, 2011).

In light of these arguments we hypothesize that people who have positive attitudes toward organic food evaluate a person who eats organic food more positively than a person who eats conventional food (Hypothesis 6). We address especially evaluations of warmth (e.g., friendliness, helpfulness, sincerity) and competence (e.g., intelligence, skill, creativity) as diverse sources of evidence have shown that they are the two universal dimensions of stereotypes (Fiske, 2000; Fiske, Cuddy, \& Glick, 2007). To check whether the participants' views of organic food consumers correspond to what is known about this group (e.g., well-educated, good income, females; Dimitri \& Dettmann, 2012; Hughner et al., 2007), we also included questions about the perceived demographics of the consumers. 


\subsection{Method}

\subsubsection{Participants and Procedure}

Six hundred and fifty-one Finnish individuals took part in the online study. Their mean age was 35 years $(S D=$ 12.34 , range $16-74)$. Of the participants, $38.6 \%$ were working, $45.2 \%$ were students, and $15.8 \%$ were otherwise occupied. A majority (58.4\%) was female, $38.23 \%$ were male. Some $(1.4 \%)$ did not want to state their sex and some rated their sex as other than male or female (1.4\%). Because these groups were small, they were again excluded from analyses which included sex comparisons.

The participants were recruited for the online study via several Facebook sites, open internet discussion forums and student mailing lists. The participants were told that the study concerned values and person perception, and confidentiality and voluntary participation were emphasized. As compensation, all participants were promised feedback about their basic values, which was based on the Short Schwartz's Value Survey (Lindeman \& Verkasalo, 2005) included in the study. Because we expected those with positive attitude toward organic food to be in majority, relatively large samples were desired for the analysis of covariance to prevent the group with less positive attitudes from being too small. Again, as the extent of participation in online surveys is difficult to predict, we sought to obtain as many participants as possible.

The first question in the online questionnaire was whether the participant's birthday fell on an uneven day or on an even day. Those who selected an uneven day were administered a questionnaire, which included an experimental story; those who selected an even day were administered the control story. Otherwise the material (described below) was identical for both groups of participants.

\subsubsection{Material}

Attitudes toward organic food, intuitive thinking style and the need for cognition were assessed as in Study 1. To examine the hypotheses about the role of positive OF attitudes in person perception, participants were categorized into two groups. Those who scored above the theoretical mean (3) on the 5-point negative - positive attitude scale (i.e., scoring 3.25 or above in this study) were categorized in the participants with a positive OF attitude group $(N=503)$, the rest of the participants were categorized in the other participants group $(N=146)$.

To examine the impact of organic food on person perceptions, we used two stories of a person called Tepa, a name which could denote a man or a woman. The control story (177 words) included a description of one day in Tepa's life, including descriptions about Tepa's work, friends, food, shopping (e.g., beans and wine), dinner, Facebook, children's education, books, and charity. The experimental story was otherwise identical, but it included a notion that Tepa prefers organic food and that Tepa bought organic beans and organic wine for the dinner.

After reading the stories, the participants were asked to give their impressions about Tepa. They were asked about Tepa's possible age and whether Tepa was more probably a woman or a man. Tepa's possible education was assessed with a 5 -point scale $(1=$ grammar school, $2=$ vocational school, $3=$ upper secondary school, $4=$ polytechnic, $5=$ university). Tepa's income was also assessed with a 5 -point scale $(1=$ much below average, $5=$ much above average).

To assess Tepa's warmth and ability, a scale from (Fiske et al., 2007)see also (Conway, Pizzamiglio, \& Mount, 1996) was used. Tepa's assumed ability $(\alpha=.71)$ was averaged from scores on the following 5 -point items $(1=$ strongly disagree, $5=$ strongly agree): competent, confident, independent, competitive, and intelligent. Tepa's warmth $(\alpha=.85)$ was averaged from scores on the items tolerant, warm, good natured, and sincere.

\subsection{Results}

We first examined the overall impression of the two stimulus persons. The results showed that the one Tepa, who ate organic food, was seen as younger $(M=33.59)$ than the Tepa, who ate non-organic food $(M=35.58)$, $F(1,623)=8.07, p=.005$. The Tepa, who ate organic food, was also assumed to have higher education than the other Tepa, $\chi^{2}(4)=15.72, p=.003$. No differences were found in the assessment of gender, $\chi^{2}(1)=0.90, p$ $=.342$, or income, $\chi^{2}(4)=4.53, p=.339$.

The main analyses focused on the way positive OF attitudes affect perceptions of Tepa. We first examined the distribution of the $\mathrm{OF}$ attitudes. They turned out to be positively skewed (skewness $=-0.75$, KolmogorovSmirnov $Z=0.12, p<.001)$. Women had more positive OF attitudes $(M=4.07)$ than men $(M=3.51), F(1,625)$ $=54.95, p<.001, \eta_{p}{ }^{2}=.081$. In addition, $\mathrm{OF}$ attitudes correlated positively with faith in intuition $\left(r_{s}=.44, p\right.$ $<.001)$, and negatively but weakly with the need for cognition $\left(r_{s}=-.16, p<.001\right)$ and with age $\left(r_{s}=-.16, p\right.$ $<.001$. Only gender and faith in intuition were included as covariates in the following analyses of variance, 
because need for cognition and age were only weakly correlated with OF attitudes. Homogeneity of variance between the groups was checked with the Levene's test for equality of variances because unequal sample sizes make ANOVA sensitive to these violations.

Although our hypotheses would allow us to proceed directly to planned comparisons, we conducted an overall ANOVA and examined all contrasts to identify unexpected results. The first analysis was conducted with Tepa's ability as the dependent variable, manipulation (experimental vs. control story) and OF attitude group (positive vs. others) as independent variables, and gender and faith in intuition as covariates. The results showed a significant main effect for gender $F(1,623)=17.08, p<.001, \eta_{p}{ }^{2}=.027$, and for attitude group, $F(1,623)=3.78$, $p=.053, \eta_{p}{ }^{2}=.006$. All other effects were non-significant $\left(p^{\prime} \mathrm{s}>.15\right)$. Levene's test for the equality of variances showed that the variances were equal, $F(3,619)=0.692, p=.557$.

The same analysis was conducted with warmth as the dependent variable. Only the covariates were related to the evaluations. Again, women gave higher warmth ratings than men, $F(1,623)=17.42, p<.001, \eta_{p}{ }^{2}=.027$. In addition, faith in intuition increased the warmth ratings, $F(1,623)=3.94, p=.048, \eta_{p}{ }^{2}=.006$. Other effects were nonsignificant $(p ' s>.15)$. Levene's test was also nonsignificant, $F(3,619)=1.776, p=.151$. As a whole, then, Hypothesis 6 was not supported, because people with positive attitudes toward organic food did not evaluate the stimulus person who ate organic food more positively than a person who ate conventional food.

However, an examination of the data revealed that participants with negative OF attitudes differed from others in their evaluations of the person who ate organic food in comparison to the person who did not. Therefore, these participants (the lowest quartile of the participants, $\mathrm{OF}$ attitudes $<3, \mathrm{~N}=99$ ) were compared with participants in the other three quartiles in the following analyses $(N=550)$. The results showed the following.

In the analysis with Tepa's ability as the dependent variables, the main effects of attitude group, $F(1,623)=7.87$, $p=.005, \eta_{p}{ }^{2}=.013$, and manipulation, $F(1,623)=4.34, p=.038, \eta_{p}{ }^{2}=.007$, were found. In addition, the interaction between attitude group and manipulation was significant, $F(1,623)=5.14, p=.024, \eta_{p}{ }^{2}=.008$. Of the covariates, the effect of gender was significant, $F(1,623)=15.95, p<.001, \eta_{p}{ }^{2}=.025$, but the effect of faith in intuition was not, $F(1,623)=0.32, p=.574, \quad \eta_{p}{ }^{2}=.001$. Levene's test showed that the variances were equal, $F(3,619)=0.991, p=.397$.

The results of the analysis with Tepas' warmth as the dependent variables showed a marginally significant main effect of attitude group, $F(1,623)=2.89, p=.090, \eta_{p}{ }^{2}=.005$, and an interaction between attitude group and manipulation, $F(1,623)=5.29, p=.022, \eta_{p}{ }^{2}=.009$. Of the covariates, the effect of gender was significant, $F(1,623)=16.58, p<.001, \eta_{p}{ }^{2}=.026$, and the effect of faith in intuition was marginally significant, $F(1,623)=$ $3.22, p=.073, \eta_{p}{ }^{2}=.005$. Levene's test showed that the variances were equal, $F(3,619)=0.547, p=.650$.

Post-hoc comparison of estimated marginal means with Bonferroni's adjustment indicated that participants with negative $\mathrm{OF}$ attitudes rated the stimulus person who ate organic food as less able, $p=.011$, but warmer than the stimulus person who ate non-organic food, $p=.020$. Other participants rated both stimulus persons equally in terms of ability $(p=.723)$ and warmth $(p=.124)$. The means of all assessments are presented in Figure 1.
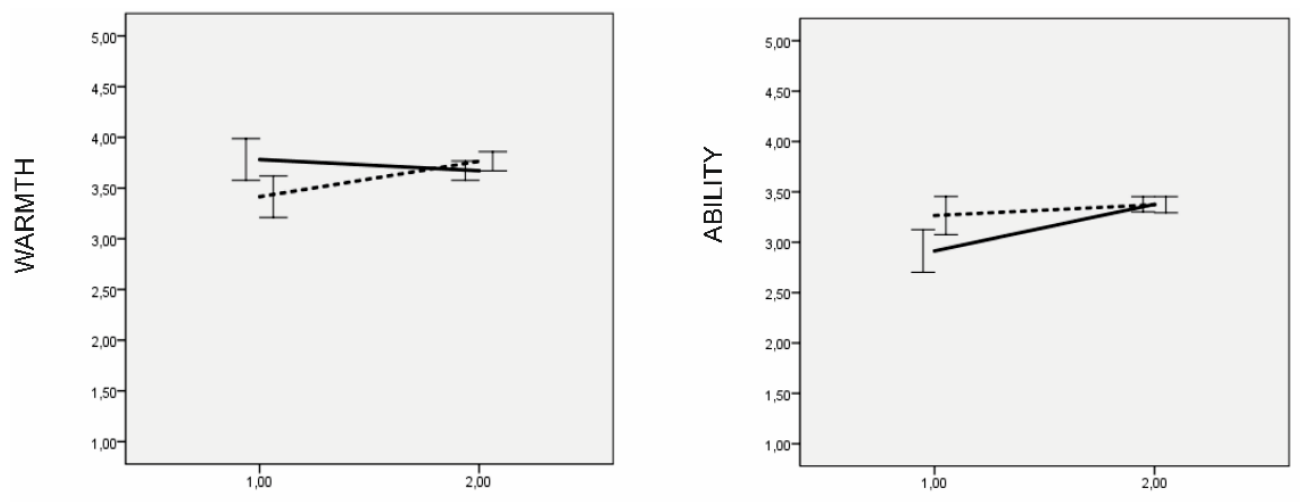

Attitude group 1= Participants with a negative OF attitude, 2 = Participants with a positive or neutral OF attitude

Figure 1. Impact of attitudes toward organic food (OF) on assessment of warmth and ability of two stimulus persons. 


\subsection{Discussion}

The participants' views about the demographics of the stimulus person who ate organic food were in line with the demographics that actually characterize organic food consumers: Tepa, who ate organic food was seen as being younger and having higher education than Tepa, who ate conventional food. Previous studies (reviews: Dimitri \& Dettmann, 2012; Hughner et al., 2007) have also shown that organic food consumers are more often younger and that they are better educated than other consumers, but the findings are not always consistent.

Contrary to our hypothesis participants with positive OF attitudes rated the two stimulus persons similarly. Instead of positive stereotypes, negative stereotypes were found: Participants, whose OF attitudes were negative, considered the stimulus person who ate organic food as warmer, but less intellectually capable than the stimulus person who ate conventional food. Although these kinds of "warm but incompetent" stereotypes are common (Fiske, 2000; Fiske et al., 2007), we did not expect that they also apply in the domain of eating organic food. Study 3 was undertaken to extend Study 2 by a different social perception task.

\section{Study 3}

Common meal times are associated with trust, belonging, and close and intimate relationships (Miller, Rozin, \& Fiske, 1998; Neely, Walton, \& Stephens, 2014; see also Koh \& Pliner, 2009). As a specific aspect of this, observing a couple sharing food leads to a greater estimate of the couple's intimacy and relationship quality (Miller et al., 1998). One may wonder if the type of food, too, has any influence. To our knowledge, the possibility that eating a particular type of food together might influence assessments of the couple's relationship has not been examined. Given the strong positive halo of organic food, and also the findings of Study 2, we analyze how people's own OF attitudes influence perception of two couples' relationship, one eating organic food and the other eating conventional food.

\subsection{Method}

\subsubsection{Participants and Procedure}

One hundred and fifty-nine Finnish individuals participated. Their mean age was 36.1 years $(S D=14.12$, range $19-73), 32.7 \%$ were working, $53.5 \%$ were students, and $11.9 \%$ were otherwise occupied $(1.9 \%$ of the responses were missing). Most of the participants (74.2\%) were females, $21.4 \%$ were male. Some $(1.9 \%)$ did not want to state their sex or rated their sex as other than male or female $(2.5 \%)$. Only men and women were included in analyses which included sex comparisons. Because the procedure was the same, the reason why the sample remained smaller than in Study 2 is not known. It is, however, possible that the research topic ("the perception of couples") was not seen as interesting as the topic in Study 2 ("person perception").

\subsubsection{Materials}

Attitudes toward organic food, faith in intuition, and the need for cognition were assessed as in Study 1. The categorization of participants in the positive $\mathrm{OF}$ attitude group $(\mathrm{N}=133)$ and in the other participants group $(\mathrm{N}=$ 26) was done as in Study 2.

The control story (171 words) described a day in a couple's life. They were simply called A and B. The story included a description of their morning and breakfast routines (e.g., eating porridge), their communication, day at work, shopping for food, and spending the evening together by eating B's favorite dinner, made by A. The experimental story was otherwise identical, but porridge was replaced with organic porridge, and the notion that the couple was very selective when purchasing food was specified in that they preferred organic products.

The story was followed by the same questions about the couple's age, education, and income as in Study 2. The participants were also asked to rate whether they assumed that the couple was a male couple, a female-male couple, or a female couple.

The couples' relationship was assessed with the ENRICH Marital Satisfaction scale (EMS, Fowers \& Olson, 1993). Three items of the original 15 -item scale were excluded because they concerned issues which were not dealt with in the stories (e.g., parenting). EMS has two subscales, marital satisfaction, and idealiztion, which refelects unrealistically positive descriptions of the marriage. In the present sudy, the term marriage was replaced with the term relationship. The participants were asked to rate the couple's relationship with seven satisfaction items $(\alpha=.81)$, for example "The couple is very happy with how they handle role responsibilities in the relationship" $(1=$ strongly disagree, $5=$ strongly agree $)$. The idealization subscale $(\alpha=.73)$ included five items, such as "The relationship is a perfect success." 


\subsection{Results}

The couple who ate organic food was assumed to have a higher income than the other couple, $\chi^{2}(3)=8.97, p$ $=.030$. Differences in the two couples' age, education, or relationship were not found $(p ' s>.12)$.

The distribution of the OF attitudes was not normal (skewness $=-1.05$, Kolmogorov- Smirnov $Z=0.17, p$ $<.001)$. In addition, women's OF attitudes $(M=4.41)$ were more positive than men's attitudes $(M=3.85)$, $F(1,151)=16.39, p<.001, \eta_{p}{ }^{2}=.099$. OF attitudes were correlated with faith in intuition $\left(r_{s}=.23, p=.004\right)$ but not with the need for cognition $\left(r_{s}=-.06, p=.426\right)$ or with age $\left(r_{s}=-.01, p=.89\right)$. Gender and faith in intuition were thus included as covariates in the following two-way analyses of variance where the impact of the manipulation (experimental vs. control story) and the OF attitude group (positive vs. others) were entered as independent variables.

The first analysis focused on the couple's satisfaction with their relationship. The results showed a significant interaction between attitude group and manipulation, $F(1,151)=8.85, p=.003, \eta_{p}{ }^{2}=.058$. The effect of faith in intuition was also significant, $F(1,151)=5.50, p=.020, \eta_{p}{ }^{2}=.037$, indicating that intuitive style increased the satisfaction ratings. Other effects were not significant ( $\mathrm{p}$ 's $>.13$ ). Levene's test was nonsignificant, $F(3,147)=$ $0.180, p=.910$.

Post-hoc comparison of estimated marginal means was conducted with Bonferroni's adjustment. In comparison to the couple who ate conventional food, participants with positive OF attitudes rated the couple's satisfaction marginally higher, if the couple ate organic food $(p=.083)$; whereas, other participants rated the couple's satisfaction lower, if the couple ate organic food $(p=.012)$.

Next, idealization of the couple's relationship was entered as the dependent variable. No significant effects were found $(p$ 's $>.12$ ). Levene's test was nonsignificant, $F(3,147)=0.401, p=.753$. Although the interaction was non-significant $(p=.122)$, post-hoc comparisons with Bonferroni's adjustment showed that participants with positive OF attitudes idealized the relationship more than others, $p=.003$. Such differences were not found among other participants, $p=.675$. All means are presented in Figure 2.
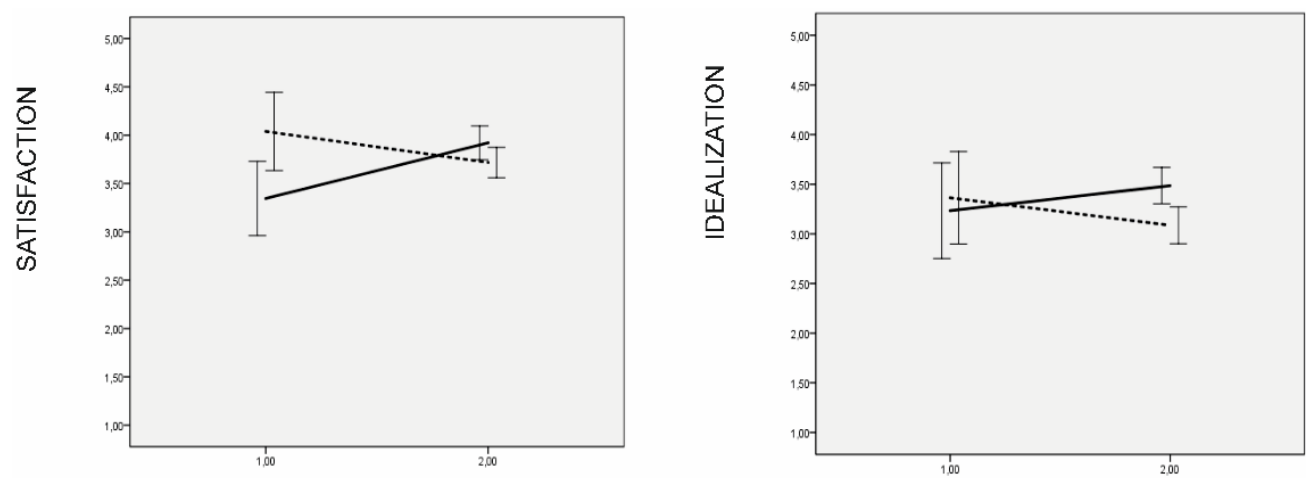

STIMULUS COUPLE

Eats organic food ------ Eats conventional food

Attitude group 1= Participants with a negative or neutral OF attitude, 2 = Participants with a positive OF attitude

Figure 2. Impact of attitudes toward organic food (OF) on perceived satisfaction in and idealization of two stimulus couple's relationship.

\section{General Discussion}

The present three studies provide evidence that organic food appeals to intuitive thinkers, and that people who eat organic food can evoke both positive and negative stereotypes. Moreover, the results of Study 1 are the first to empirically demonstrate the close link between attitudes toward organic food, food additives and processed food. All three attitudes were predicted by the same variables and roughly to the same extent, indicating that attitudes toward organic food, food additives, and processed foods, are not different kinds of attitudes but only different viewpoints on the same object, natural type food.

\subsection{Thinking Styles and Belief in Health Myths Predicted OF Attitudes}

Analytical thinking style played only a small part in OF attitudes. Although positive attitudes were weakly associated with a low need for cognition in Studies 1 and 2, the association was not found in Study 3 and it disappeared when the other cognitive factors were held constant. Another indicator of analytical style, success in the Cognitive Reflection Test, had a bit stronger negative association with OF attitudes but it did not have a 
unique effect either. While not supporting our hypothesis, these results concur with Saher et al.'s (2006) findings, and imply that people who are deliberate and reflective in their thinking may have less positive OF attitudes than others but the association is weak and confounded with other cognitive dispositions.

In line with Saher et al.'s (2006) results, the positive OF attitudes increased when faith in intuition increased. This association was found in all three studies, and Study 1 further showed that faith in intuition was the strongest and independent predictor of positive OF attitudes.

Other indicators of intuitive style evinced the same pattern of results, supporting our hypotheses. People who thought positively about $\mathrm{OF}$, were more dichotomic in their thinking, displaying a tendency to regard food and diets as either good or bad, rather than something that can be both or in between. More than other participants, they also saw knowledge in general to be simple and unambiguous - an epistemology that is typical for people who avoid ambiguity and seek single answers (a review: Hofer \& Pintrich, 1997). Finally, believing in unfounded health myths, including beliefs that vaccines cause autism, were more typical for people with positive OF attitudes. Beliefs in health myths were also strongly and positively related to an intuitive thinking style. These results add to previous research demonstrating that relying on intuition is often (but not always) related to different types of reasoning biases (Gilovich, Griffin, \& Kahneman, 2002; Phillips, Fletcher, Marks, \& Hine, 2015).

The main question is why intuitive thinking so powerfully predicts positive attitudes toward organic food? We raise two possibilities. First, repeated exposure to a particular content boosts positive attitudes, and this effect seems to be enhanced among intuitive thinkers (Sundar et al., 2015). Second, it is possible that the widespread idea that natural is good (Rozin, 2006; Rozin et al., 2012) is intrinsic to human beings and that the idea is accentuated among people who rely on their intuition. According to Stanovich (2004), some beliefs are widespread because they are good fits to intuitive domain-specific learning devices that have been adaptive in our evolutionary past. We propose that "natural is good" is such a belief because until food production, agriculture and pharmacy were industrialized, human beings and their ancestors obtained all nutrition and medication from nature, requiring a positive attitude and approach motivation toward nature despite all its hazards.

\subsection{Eating Organic Food Evoked Positive and Negative Stereotypes}

In line with previous findings and arguments (Epstein et al., 1996; Kahneman \& Frederick, 2002; Plessner, Betsch, \& Betsch, 2008), individuals with intuitive thinking style were more likely to endorse a (positive) stereotype, making more positive judgments about the stimulus persons and couples in Studies 2 and 3. However, the key factor in the stereotypes was the participants' own attitude toward organic food. We expected that people who view organic food positively, evaluate a stimulus person (Study 2) or a couple (Study 3) who eats organic food more positively than a stimulus person or a couple who does not. However, this effect was found only in Study 3. Participants with a positive OF attitude evaluated the OF couple's relationship as happier and overall as more satisfactory than the other couple's relationship (although this difference was only marginally significant). They also idealized the OF couple's relationship more than the other couple's relationship by agreeing with statements which depicted the relationship in unrealistically positive terms.

These results coincide with findings from several lines of studies. Research on the similarity bias (a review: Montoya \& Horton, 2013), myside bias (Stanovich, West, \& Toplak, 2013) show that we are prone to evaluate positively individuals who are like ourselves. As our stimulus couple only ate together, the results also extend the findings about food sharing (Miller et al., 1998) by showing that sharing the food is not necessary for the impression about a positive social relationship, eating praiseworthy food together may suffice. The findings are also closely related to the other stereotypical judgments based on what people eat, most often associated with masculine vs. feminine diet or vegetarian vs. meat-based diet (Vartanian, 2015; Vartanian et al., 2007).

Surprisingly, OF eaters evoked negative stereotypes among those whose own OF attitudes were indifferent or negative. Participants with negative or indifferent OF attitudes estimated that the relationship of the couple who ate organic food was less satisfactory than the other couple's relationship (Study 3). Moreover, in Study 2 the participants with negative OF attitudes regarded the stimulus person who ate organic food as less competent but warmer than the stimulus person who ate conventional food. This "warm but incompetent" attitude is one of the main stereotypes, communicating subordinate status but paternalistic positivity toward groups that elicit pity and sympathy (Cuddy, Fiske, \& Glick, 2007; Fiske, 2000). So far, this stereotype has been found to concern especially people who are older, physically disabled or mentally disabled (a review: Fiske et al., 2007). According to the present results, people who do not prefer organic food seem to think that organic food consumers belong to the same crowd. 


\subsection{Limitations}

Several limitations need to be considered when interpreting the results. First, the samples of the studies were biased toward well-educated people with positive OF attitudes, resulting in small sample sizes in the groups with neutral or negative OF attitudes. Especially the results of Study 2 must be taken with caution, because the analyses were not planned but were based on explorative post hoc analyses. In addition, apart from the Cognitive Reflection Test, Study 1 was based on self-report. Moreover, many effect sizes were small. However, we would like to agree with Cortina, Landis, Lance, and Vandenberg (2009) in that small effect sizes are not necessarily trivial: if a phenomenon can be detected in spite of subtle manipulations, small effect sizes can justify even strong conclusions.

\subsection{Conclusion}

The aim of the present series of studies was not to question the possibility that organic agriculture turns out to be more sustainable or otherwise superior than traditional agriculture in the future. For the present, however, consumers are spending huge amounts of money on organic purchases, and organic farmlands are increasing by millions of hectares every year (e.g., EU Comission, 2017), even though scientific evidence for the benefits is mixed. This paradox induces us to view the high regard of organic food as a meme; not in genetic terms, but as a cultural artefact (Heath, Bell, \& Sternberg, 2001) that spreads from person to person, that affects social cognition, and that propagates in the social environment as a true statement to be believed.

\section{Acknowledgments}

We thank our students for collecting the data and for developing the stories for Studies 2 and 3: Karolina Ginman, Johanna Immonen, Soila Kaisto, Leena Lindqvist, Veera Malkki, Minna Parvio, Ilja Salakka, Elina Särkilahti, Niko Toroskainen, and Suvi Virtanen.

\section{References}

Academics Review (n.d.). Organic marketing report (pdf). Retrieved from http://academicsreview.org/wp-content/uploads/2014/04/AR_Organic-Marketing-Report_Print.pdf

Arvola, A., Vassallo, M., Dean, M., Lampila, P., Saba, A., Lähteenmäki, L., \& Shepherd, R. (2008). Predicting intentions to purchase organic food: The role of affective and moral attitudes in the Theory of Planned Behaviour. Appetite, 50, 443-454. https://doi.org/10.1016/j.appet.2007.09.010

Bartels, J., \& Hoogendam, K. (2011). The role of social identity and attitudes toward sustainability brands in buying behaviors for organic products. Journal of Brand Management, 18, 697-708. https://doi.org/10.1057/bm.2011.3

Byrne, S. M., Allen, K. L., Dove, E. R., Watt, F. J., \& Nathan, P. R. (2008). The reliability and validity of the dichotomous thinking in eating disorders scale. Eating Behaviors, 9, 154-162. https://doi.org/10.1016/j.eatbeh.2007.07.002

Conway, M., Pizzamiglio, M. T., \& Mount, L. (1996). Status, communality, and agency: Implications for stereotypes of gender and other groups. Journal of Personality and Social Psychology, 71, 25-38. https://doi.org/0.1037/0022-3514.71.1.25

Cortina, J. M., Landis, R. S., Lance, C., \& Vandenberg, R. (2009). When small effect sizes tell a big story, and when large effect sizes don't. In C. E. Lance \& R. J. Vandenberg (Eds.), Statistical and methodological myths and urban legends: Doctrine, verity and fable in the organizational and social sciences (pp. 287-308). New York: Routledge.

Cuddy, A. J., Fiske, S. T., \& Glick, P. (2007). The BIAS map: Behaviors from intergroup affect and stereotypes. Journal of Personality and Social Psychology, 92, 631-648. https://doi.org/10.1037/0022-3514.92.4.631

Dangour, A. D., Dodhia, S. K., Hayter, A., Allen, E., Lock, K., \& Uauy, R. (2009). Nutritional quality of organic foods: A systematic review. The American Journal of Clinical Nutrition, 90, 680-685. https://doi.org/10.3945/ajen.2009.28041

Dangour, A. D., Lock, K., Hayter, A., Aikenhead, A., Allen, E., \& Uauy, R. (2010). Nutrition-related health effects of organic foods: A systematic review. The American Journal of Clinical Nutrition, 92, 203-210. https://doi.org/10.3945/ajen.2010.29269

Dimitri, C., \& Dettmann, R. L. (2012). Organic food consumers: What do we really know about them? British Food Journal, 114, 1157-1183. https://doi.org/10.1108/00070701211252101 
Epstein, S., Pacini, R., Denes Raj, V., \& Heier, H. (1996). Individual differences in intuitive-experiential and analytical-rational thinking styles. Journal of Personality and Social Psychology, 71, 390-405. https://doi.org/10.1037/0022-3514.71.2.390

EU Comission (2017). Organic farming. Agriculture and rural development, from https://ec.europa.eu/agriculture/organic/organic-farming_en

Fiske, S. T. (2000). Stereotyping, prejudice, and discrimination at the seam between the centuries: Evolution, culture, mind, and brain. European Journal of Social Psychology, 30, 299-322. https://doi.org/10.1002/(SICI)1099-0992(200005/06)30:3<299::AID-EJSP2>3.0.CO;2-F

Fiske, S. T., Cuddy, A. J. C., \& Glick, P. (2007). Universal dimensions of social cognition: Warmth and competence. Trends in Cognitive Sciences, 11, 77-83. https://doi.org/10.1016/j.tics.2006.11.005

Fowers, B. J., \& Olson, D. H. (1993). ENRICH Marital Satisfaction Scale: A brief research and clinical tool. Journal of Family Psychology, 7, 176. https://doi.org/10.1037/0893-3200.7.2.176

Frederick, S. (2005). Cognitive reflection and decision making. The Journal of Economic Perspectives, 19, 25-42. https://doi.org/10.1257/089533005775196732

Gilovich, T., Griffin, D., \& Kahneman, D. (Eds.). (2002). Heuristics and biases. The psychology of intuitive judgment. Cambridge: Cambridge University Press.

Haugtvedt, C. P., Petty, R. E., \& Cacioppo, J. T. (1992). Need for cognition and advertising: Understanding the role of personality variables in consumer behavior. Journal of Consumer Psychology, 1, 239-260. https://doi.org/10.1016/S1057-7408(08)80038-1

Heath, C., Bell, C., \& Sternberg, E. (2001). Emotional selection in memes: The case of urban legends. Journal of Personality and Social Psychology, 81, 1028-1041. https://doi.org/10.1037/0022-3514.81.6.1028

Hodgkinson, G. P., Langan-Fox, J., \& Sadler-Smith, E. (2008). Intuition: A fundamental bridging construct in the behavioural sciences. British Journal of Psychology, 99, 1-27. https://doi.org/10.1348/000712607X216666

Hofer, B. K., \& Pintrich, P. R. (1997). The development of epistemological theories: Beliefs about knowledge and knowing and their relation to learning. Review of Educational Research, 67, 88-140. https://doi.org/10.3102/00346543067001088

Hsu, S.-Y., Chang, C.-C., \& Lin, T. T. (2016). An analysis of purchase intentions toward organic food on health consciousness and food safety with/under structural equation modeling. British Food Journal, 118, 200-216. https://doi.org/10.1108/BFJ-11-2014-0376

Hughner, R. S., McDonagh, P., Prothero, A., Shultz, C. J., \& Stanton, J. (2007). Who are organic food consumers? A compilation and review of why people purchase organic food. Journal of Consumer Behaviour, 6, 94-110. https://doi.org/10.1002/cb.210

IFOAM EU Group (2016). Organic in Europe: Prospects and developments (pdf), from www.ifoam-eu.org

Kahneman, D., \& Frederick, S. (2002). Representativeness revisited: Attribute substitution in intuitive judgment. In T. Gilovich, R. Griffin \& D. Kahneman (Eds.), Heuristics and biases: The psychology of intuitive judgment (pp. 49-81). Cambridge: Cambridge University Press.

Koh, J., \& Pliner, P. (2009). The effects of degree of acquaintance, plate size, and sharing on food intake. Appetite, 52, 595-602. https://doi.org/10.1016/j.appet.2009.02.004

Li, M., \& Chapman, G. B. (2012). Why do people like natural? Instrumental and ideational bases for the naturalness preference. Journal of Applied Social Psychology, 42, 2859-2878. https://doi.org/10.1111/j.1559-1816.2012.00964.x

Lindeman, M., \& Verkasalo, M. (2005). Measuring values with the Short Schwartz's Value Survey. Journal of Personality Assessment, 85, 170-178. https://doi.org/10.1207/s15327752jpa8502_09

Lockie, S., Lyons, K., Lawrence, G., \& Grice, J. (2004). Choosing organics: A path analysis of factors underlying the selection of organic food among Australian consumers. Appetite, 43, 135-146. https://doi.org/10.1016/j.appet.2004.02.004

Magkos, F., Arvaniti, F., \& Zampelas, A. (2006). Organic food: Buying more safety or just peace of mind? A critical review of the literature. Critical Reviews in Food Science and Nutrition, 46, 23-56. https://doi.org/10.1080/10408690490911846 
Miller, L., Rozin, P., \& Fiske, A. P. (1998). Food sharing and feeding another person suggest intimacy: Two studies of American college students. European Journal of Social Psychology, 28, 423-436. https://doi.org/10.1002/(SICI)1099-0992(199805/06)28:3<423::AID-EJSP874>3.0.CO;2-V

Montoya, R. M., \& Horton, R. S. (2013). A meta-analytic investigation of the processes underlying the similarity-attraction effect. Journal of Social and Personal Relationships, 30, 64-94. https://doi.org/10.1177/0265407512452989

Neely, E., Walton, M., \& Stephens, C. (2014). Young people's food practices and social relationships. A thematic synthesis. Appetite, 82, 50-60. https://doi.org/10.1016/j.appet.2014.07.005

Norris, P., \& Epstein, S. (2011). An experiential thinking style: Its facets and relations with objective and

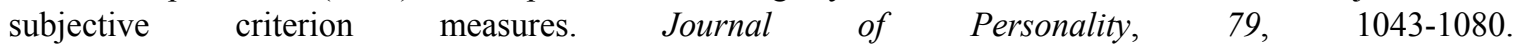
https://doi.org/10.1111/j.1467-6494.2011.00718.x

Phillips, W. J., Fletcher, J. M., Marks, A. D., \& Hine, D. W. (2015). Thinking styles and decision making: A meta-analysis. Psychological Bulletin, 142, 269-290. https://doi.org/10.1037/bul0000027

Plessner, H., Betsch, C., \& Betsch, T. (Eds.). (2008). Intuition in judgment and decision making. New York: Erlbaum.

Prada, M., Garrido, M. V., \& Rodrigues, D. (2017). Lost in processing? Perceived healthfulness, taste and caloric content of whole and processed organic food. Appetite, 114, 175-186. https://doi.org//10.1016/j.appet.2017.03.031

Prada, M., Rodrigues, D., \& Garrido, M. V. (2016). Deliberate choices or strong motives: Exploring the mechanisms underlying the bias of organic claims on leniency judgments. Appetite, 103, 8-16. https://doi.org/10.1016/j.appet.2016.03.012

Rosen, J. D. (2010). A review of the nutrition claims made by proponents of organic food. Comprehensive Reviews in Food Science and Food Safety, 9, 270-277. https://doi.org/10.1111/j.1541-4337.2010.00108.x

Rothgerber, H. (2015). Can you have your meat and eat it too? Conscientious omnivores, vegetarians, and adherence to diet. Appetite, 84, 196-203. https://doi.org/10.1016/j.appet.2014.10.012

Rozin, P. (2005). The meaning of "natural" process more important than content. Psychological Science, 16, 652-658. https://doi.org/10.1111/j.1467-9280.2005.01589.x

Rozin, P. (2006). Naturalness judgments by lay Americans: Process dominates content in judgments of food or water acceptability and naturalness. Judgment and Decision Making, 1, 91-97.

Rozin, P., Ashmore, M., \& Markwith, M. (1996). Lay American conceptions of nutrition: Dose insensitivity, categorical thinking, contagion, and the monotonic mind. Health Psychology, 15, 438-447. https://doi.org/10.1037/0278-6133.15.6.438

Rozin, P., Fischler, C., \& Shields-Argelès, C. (2012). European and American perspectives on the meaning of natural. Appetite, 59, 448-455. https://doi.org/10.1016/j.appet.2012.06.001

Rozin, P., Spranca, M., Krieger, Z., Neuhaus, R., Surillo, D., Swerdlin, A., \& Wood, K. (2004). Preference for natural: Instrumental and ideational $/$ moral motivations, and the contrast between foods and medicines. Appetite, 43, 147-154. https://doi.org/10.1016/j.appet.2004.03.005

Saher, M., Lindeman, M., \& Koivisto-Hursti, U. K. (2006). Attitudes towards genetically modified and organic foods. Appetite, 46, 324-331. https://doi.org/10.1016/j.appet.2006.01.015

Schommer, M. (1990). Effects of beliefs about the nature of knowledge on comprehension. Journal of Educational Psychology, 82, 498-504. https://doi.org//10.1037/0022-0663.82.3.498

Schraw, G., Bendixen, L., \& Dunkle, M. (2002). Development and validation of the Epistemic Belief Inventory (EBI). In B. Hofer \& P. Pintrich (Eds.), Personal epistemology: The psychology of beliefs about knowledge and knowing (pp. 261-275). Mahwah, NJ: Erlbaum.

Seufert, V., Ramankutty, N., \& Foley, J. A. (2012). Comparing the yields of organic and conventional agriculture. Nature, 485, 229-232. https://doi.org/10.1038/nature11069

Slovic, P., Finucane, M. L., Peters, E., \& MacGregor, D. G. (2004). Risk as analysis and risk as feelings: Some thoughts about affect, reason, risk, and rationality. Risk analysis, 24, 311-322. https://doi.org/10.1111/j.0272-4332.2004.00433.x 
Smith-Spangler, C., Brandeau, M. L., Hunter, G. E., Bavinger, J. C., Pearson, M., Eschbach, P. J., . . Stave, C. (2012). Are organic foods safer or healthier than conventional alternatives? A systematic review. Annals of Internal Medicine, 157, 348-366. https://doi.org/10.7326/0003-4819-157-5-201209040-00007

Sparks, P., \& Shepherd, R. (1992). Self-identity and the theory of planned behavior: Assesing the role of identification with" green consumerism. Social Psychology Quarterly, 55, 388-399. https://doi.org/10.2307/2786955

Stanovich, K. E. (2004). The robot's rebellion: Finding meaning in the age of Darwin. London: University of Chicago Press.

Stanovich, K. E. (2012). On the distinction between rationality and intelligence: Implications for understanding individual differences in reasoning. In K. J. Holyoak \& R. G. Morrison (Eds.), The Oxford handbook of thinking and reasoning (pp. 343-365). New York: Oxford University Press.

Stanovich, K. E., West, R. F., \& Toplak, M. E. (2013). Myside bias, rational thinking, and intelligence. Current Directions in Psychological Science, 22, 259-264. https://doi.org/10.1177/0963721413480174

Statista (n.d.). Organic food-sales in the US since 2000, from https://www.statista.com/statistics/196952/organic-food-sales-in-the-us-since-2000

Sundar, A., Kardes, F. R., \& Wright, S. A. (2015). The influence of repetitive health messages and sensitivity to fluency on the truth effect in advertising. Journal of Advertising, 44, 375-387. https://doi.org/10.1080/00913367.2015.1045154

Swami, V., Stieger, S., Pietschnig, J., Nader, I. W., \& Voracek, M. (2012). Using more than $10 \%$ of our brains: Examining belief in science-related myths from an individual differences perspective. Learning and individual differences, 22, 404-408. https://doi.org/10.1016/j.lindif.2011.12.005

Sörqvist, P., Haga, A., Langeborg, L., Holmgren, M., Wallinder, M., Nöstl, A., . . Marsh, J. E. (2015). The green halo: Mechanisms and limits of the eco-label effect. Food Quality and Preference, 43, 1-9. https://doi.org/10.1016/j.foodqual.2015.02.001

Tabachnick, B. G., \& Fidell, L. S. (2013). Using multivariate statistics. Boston: Pearson.

van Huylenbroek, G., Mondelaers, K., Aertsens, J., Mondelaers, K., Aertsens, J., \& Van Huylenbroeck, G. (2009). A meta-analysis of the differences in environmental impacts between organic and conventional farming. British Food Journal, 111, 1098-1119. https://doi.org/10.1108/00070700910992925

Vartanian, L. R. (2015). Impression management and food intake. Current directions in research. Appetite, 86, 74-80. https://doi.org/10.1016/j.appet.2014.08.021

Vartanian, L. R., Herman, C. P., \& Polivy, J. (2007). Consumption stereotypes and impression management: How you are what you eat. Appetite, 48, 265-277. https://doi.org/10.1016/j.appet.2006.10.008

Wiedmann, K.-P., Hennigs, N., Henrik Behrens, S., \& Klarmann, C. (2014). Tasting green: An experimental design for investigating consumer perception of organic wine. British Food Journal, 116, 197-211. https://doi.org/10.1108/BFJ-04-2012-0090

Williams, C. M. (2002). Nutritional quality of organic food: Shades of grey or shades of green? Proceedings of the Nutrition Society, 61, 19-24. https://doi.org/10.1079/PNS2001126

Zajonc, R. B. (1968). Attitudinal effects of mere exposure. Journal of Personality and Social Psychology, 9 , 1-27. https://doi.org/10.1037/h0025848

\section{Copyrights}

Copyright for this article is retained by the author(s), with first publication rights granted to the journal.

This is an open-access article distributed under the terms and conditions of the Creative Commons Attribution license (http://creativecommons.org/licenses/by/3.0/). 